\title{
3D Interconnected Macro-mesoporous Electrode with Self-assembled NiO nanodots for High-performance Supercapacitor-like Li-ion Battery
}

Xianfeng Zheng ${ }^{\mathrm{a}}$, Hongen Wang ${ }^{\mathrm{a}}$, Chao Wang ${ }^{\mathrm{a}}$, Zhao Deng ${ }^{\mathrm{a}}$, Lihua Chen, ${ }^{\mathrm{a}} \mathrm{Yu} \mathrm{Li},{ }^{\mathrm{a} *}$ Tawfique $\operatorname{Hasan}^{\mathrm{b}, \mathrm{c}}$ and Bao-Lian $\mathrm{Su}^{\mathrm{a}, \mathrm{d}, \mathrm{e}, *}$

${ }^{\mathrm{a}}$ Laboratory of Living Materials at the State Key Laboratory of Advanced Technology for Materials Synthesis and Processing, Wuhan University of Technology, 122 Luoshi Road, 430070 Wuhan, Hubei, China; Email: yu.li@whut.edu.cn and baoliansu@whut.edu.cn

${ }^{\mathrm{b}}$ Cambridge Graphene Centre, University of Cambridge, Cambridge, CB3 OFA, UK

${ }^{c}$ Nanoscience Centre, University of Cambridge, Cambridge CB3 OFF, UK

${ }^{\mathrm{d}}$ Laboratory of Inorganic Materials Chemistry (CMI), University of Namur, 61 rue de Bruxelles, B-5000 Namur, Belgium; E-mail: bao-lian.su@unamur.be

${ }^{\mathrm{e}}$ Department of Chemistry and Clare Hall, University of Cambridge, Cambridge CB2 IEW, UK; E-mail: $\underline{b l s 26 @ c a m . a c . u k}$ 


\begin{abstract}
We report a binder-free three-dimensional (3D) macro-mesoporous electrode architecture via self-assembly of $3 \mathrm{~nm} \mathrm{NiO}$ nanodots on macroporous nickel foam for high performance supercapacitor-like lithium battery. This electrode architecture provides a hierarchically 3D macro-mesoporous electrolyte-filled network that simultaneously enables rapid ion transfer and ultra-short solid-phase ion diffusion. Benefitting from the structural superiority owing to the interconnected porous hierarchy, the electrode exhibits supercapacitor-like high rate capabilities with high lithium battery capacities during the discharge-charge process: a very high capacity of $518 \mathrm{~mA} \mathrm{~h} \mathrm{~g}^{-1}$ at an ultrahigh current density of $50 \mathrm{~A} \mathrm{~g}^{-1}$. It exceeds at least $\sim 10$ times than that of the state-of-art graphite anode, which shows only $\sim 50 \mathrm{~mA} \mathrm{~h} \mathrm{~g}^{-1}$ at $\sim 2-3 \mathrm{~A} \mathrm{~g}^{-1}$ as anode for Li-ion battery. The preparation method to 3D interconnected hierarchically macro-mesoporous electrode, presented here can provide an efficient new binder free-electrode technique towards the development of high-performance supercapacitor-like Li-ion batteries.
\end{abstract}

Keywords: NiO, Nanodots, Self-assembly, Supercapacitor, Lithium-ion Battery 


\section{Introduction}

In recent years, the search for high-performance electrochemical energy storage devices have drawn significant attention due to the fossil-fuel crisis and ever-increasing demand for renewable energy in the modern society. [1] Indeed, storing high-density energy at high charge-discharge rate is strongly desired by the technology companies and consumers alike. [2, 3] Conventionally, electrochemical supercapacitors deliver high power density $\left(1-10 \mathrm{~kW} \mathrm{~kg}^{-1}\right)$ but low energy density (1-10 $\mathrm{Wh} \mathrm{kg}^{-1}$ ) as they involve non-solid state ion diffusion and only store energy by surface adsorption reactions of charged species on an electrode material. [4-6] By storing charge in the bulk of a material via conversion or alloying-dealloying reaction, Li-ion batteries (LIBs) offer high energy density $\left(100 \mathrm{Wh} \mathrm{kg}^{-1}\right)$ but low power density $\left(0.1 \mathrm{~kW} \mathrm{~kg}^{-1}\right)$ due to the poor rate capabilities of electrodes suffering from formidable diffusion kinetic problems. [4, 7] A Li-ion energy-storage device that combines the high capacity of LIBs with the high-rate performance characteristics of supercapacitors, namely supercapacitor-like Li-ion battery, can significantly advance the technology involving electric and plug-in hybrid electric vehicles and storage for wind and solar energy.

Such a Li-ion battery would generally require three-dimensional (3D) electrode architecture for providing rapid ion transfer in electrolyte-filled porous networks and excellent electron conduction. [3] Superior to the traditional copper foil (CF) electrode and irregular porous carbon-black, conductive metal foam electrodes with a 3D interconnected macroporous network offer a binder-free electrode configuration and have recently proven to be particularly promising. [3, 8-11] For solid-state Li-ion diffusion, the mean diffusion time $\tau_{e q}$ for diffusion is proportional to the square of the characteristic dimensions of active materials $L$ by the following formula, $\tau_{e q}=L^{2} / 2 D$, where $D$ is the diffusion coefficient. $[3,12,13]$ This means that reducing the particle-size should very effectively boost the rate capability of batteries. In this context, well-defined, nanosized active materials with mesopores for electrolyte access are widely sought, but are currently restricted to a relatively large particle-size of $\sim 50 \mathrm{~nm}$. [12-15] Thus far, only modest rate-performance improvements (0.1-2 $\left.\mathrm{A} \mathrm{g}^{-1}\right)$ have been archived in these anode materials based on transition-metal oxides. $[10,11,14]$ Previously investigated routes include chemical treatment at high-temperature and solution growth in hydrothermal reaction, which can be used to produce coating of compatible materials on macroporous nickel foam (NF), such as $\mathrm{NiP}_{2}, \mathrm{Ni}_{3} \mathrm{~S}_{2}, \mathrm{Co}_{3} \mathrm{O}_{4}$ and $\mathrm{CoO}$. [10, 14-16] However, further reducing the particle-size has been proved to be very challenging. [10, 14-17] As 
an alternative route, self-assembling pre-synthesized nanoparticles on NF could be a more feasible pathway, because their sizes are readily tunable during the solution-phase synthesis procedure. [18-22] Among the transition metal oxides, nickel oxide (NiO) is a very promising anode material due to its high theoretical capacity $\left(718 \mathrm{~mA} \mathrm{~h} \mathrm{~g}\right.$ for $2 \mathrm{Li}^{+}$per $\left.\mathrm{NiO}\right)$ and good chemical compatibility with NF substrate. [23] Based on the above considerations, self-assembling ultra-small $\mathrm{NiO}$ nanoparticles on macroporous $\mathrm{NF}$ to fabricate a 3D interconnected macro-mesoporous $\mathrm{NiO}$ electrode is thus expected to be very suitable for high performance supercapacitor-like Li-ion battery.

Herein, we report a binder-free electrode architecture via self-assembling electrolytically active $3 \mathrm{~nm} \mathrm{NiO}$ nanodots to form uniform mesopores on macroporous NF. Such electrode architecture provides a hierarchically 3D interconnected macro-mesoporous electrolyte-filled network, which simultaneously enables rapid ion transfer in electrolyte and ultra-short ion diffusion length in solid-phase. Benefitting from the structural superiority, the $3 \mathrm{~nm} \mathrm{NiO} / \mathrm{NF}$ exhibits supercapacitor-like rate capabilities while maintaining high battery capacities during charge-discharge process. In particular, it displays superior charge-discharge stability and ultrahigh rate capability with a capacity of $518 \mathrm{~mA} \mathrm{~h} \mathrm{~g}^{-1}$ at $50 \mathrm{~A} \mathrm{~g}^{-1}$. The $3 \mathrm{D}$ interconnected macro-mesoporous architecture, facilitated by the self-assembled $3 \mathrm{~nm} \mathrm{NiO}$ nanodots on $\mathrm{NF}$ presented here is a significant step towards the development of high-performance supercapacitor-like Li-ion batteries.

\section{Materials and synthesis}

\section{Materials synthesis and self-assembly}

Nickel (acetylacetonate) $)_{2}\left(\mathrm{Ni}(\mathrm{acac})_{2}, 99 \%\right.$, Aldrich), oleylamine (96\%, Aldrich), ethanol and hexane are used as received. For synthesizing $3 \mathrm{~nm} \mathrm{NiO}$, a mixture of oleylamine $(8 \mathrm{~g})$ and $\mathrm{Ni}(\mathrm{acac})_{2}(1 \mathrm{~g})$ is heated to $100{ }^{\circ} \mathrm{C}$ with magnetically stirring under a flow of $\mathrm{O}_{2}$. The utilization of oxygen atmosphere can ensure the formation of $\mathrm{NiO}$. The solution is heated to $200{ }^{\circ} \mathrm{C}$ quickly and kept at this temperature for $30 \mathrm{~min}$. After cooling to room temperature naturally, excess ethanol is added to the solution to induce precipitation, which is then collected via centrifugation. The NiO nano-dots are repeatedly washed, isolated and dried, and are finally dispersed in hexane to form a 
dispersion. Residual amines are removed via ethanol wash, as verified by FTIR spectroscopy. The $30 \mathrm{~nm} \mathrm{NiO}$ nanoparticles are prepared by seed-mediated growth. oleylamine $(8 \mathrm{~g})$ and $\mathrm{Ni}(\mathrm{acac})_{2}$ (1.04 g) are mixed and magnetically stirred $100{ }^{\circ} \mathrm{C}$ under oxygen atmosphere. $90 \mathrm{mg}$ of $3 \mathrm{~nm} \mathrm{NiO}$ nanodots dispersed in hexane is added to the hot solution as seed. The mixture is rapidly heated to $200{ }^{\circ} \mathrm{C}$ and kept at this temperature for $30 \mathrm{~min}$. This produces a hexane dispersion of $30 \mathrm{~nm} \mathrm{NiO}$ nanoparticles. For the self-assembly of $\mathrm{NiO}$ nanodots/nanoparticles, the nickel foam (NF) and the copper foil (CF) are separately immersed in $1.5 \mathrm{mg} / \mathrm{mL} \mathrm{NiO}$ nanodot/nanoparticle hexane dispersion. During the hexane evaporation, the NiO nanoparticles are self-assembled on to NF or CF. After degassing at $250{ }^{\circ} \mathrm{C}$ under vacuum, $3 \mathrm{~nm} \mathrm{NiO} / \mathrm{NF}$ (mass loading: $3.6 \mathrm{mg} \mathrm{cm}^{-2}$ ), $30 \mathrm{~nm}$ $\mathrm{NiO} / \mathrm{NF}$ (mass loading: $3.7 \mathrm{mg} \mathrm{cm}^{-2}$ ) and $3 \mathrm{~nm} \mathrm{NiO} / \mathrm{CF}$ (mass loading: $3.4 \mathrm{mg} \mathrm{cm}^{-2}$ ) are obtained. Only one side of the samples is in direct contact with the $\mathrm{NiO}$ suspension while the other side is protected using sticky tape.

\section{Characterizations}

The TEM images are acquired using a JEM-2100F with $200 \mathrm{kV}$ acceleration voltage. The SEM images are taken using a Hitachi S-4800. The XRD pattern is obtained using a Bruker D8 Advance diffractometer equipped with a $\mathrm{Cu} \mathrm{K}_{\mathrm{a}}$ rotating anode source. The pore-size distribution is acquired by a Micromeritics ASAP 2020 porosimeter. The samples are degassed at $120{ }^{\circ} \mathrm{C}$ for $12 \mathrm{~h}$ before measurement. The mesopore size is calculated using the Barrett-Joyner-Halenda (BJH) model. The surface area is obtained by Brunauer-Emmett-Teller (BET) method.

\section{Electrochemical measurement}

The electrochemical measurements of electrodes for supercapacitor are performed in a three electrode electrochemical cell at room temperature using $6 \mathrm{M} \mathrm{KOH}$ as the electrolyte. The as-prepared $3 \mathrm{~nm} \mathrm{NiO/NF}$ acted directly as the working electrode. A Pt plate and $\mathrm{Ag} / \mathrm{AgCl}$ are used as the counter electrode and the reference electrode, respectively. All potentials are referred to the reference electrode. The weight-specific capacitance $\left[\mathrm{F} \mathrm{g}^{-1}\right]$ and current rate $\left[\mathrm{A} \mathrm{g}^{-1}\right]$ are calculated based on the mass of $\mathrm{NiO}$. The electrochemical performance of electrodes for Li-ion battery is evaluated via a CR2032-tpye coin cell on a LAND (CT2001A) multichannel battery test system. Batteries are assembled using $3 \mathrm{~nm} \mathrm{NiO} / \mathrm{NF}$ as the working electrode, $1 \mathrm{M}$ solution of $\mathrm{LiPF}_{6}$ in ethylene carbon (EC)/diethyl carbonate (DEC) (1:1, in wt \%) as electrolyte, and a lithium foil as the 
counter electrode. Galvanostatic discharge/charge measurements are performed on a CHI 660D in a potential range of $3 \mathrm{~V}-0.02 \mathrm{~V}$ vs $\mathrm{Li}^{+} / \mathrm{Li}$. The specific energy $E(\mathrm{~W} \mathrm{~h} \mathrm{~kg}$ ) is calculated by the integration of specific capacity and voltage from the discharge curves. The specific power $P$ (W $\mathrm{kg}^{-1}$ ) is calculated by the product of average voltage and discharge current, where the average voltage is the voltage when the capacity reaching $50 \%$ of the final value.

\section{Results and discussions}

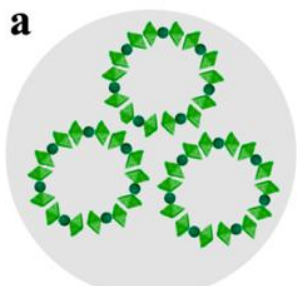

Metal-organic molecular cluster

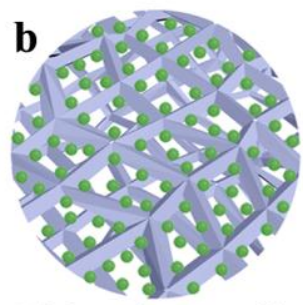

$\mathrm{Ni}$ foam immersed in $\mathrm{NiO}$ suspension

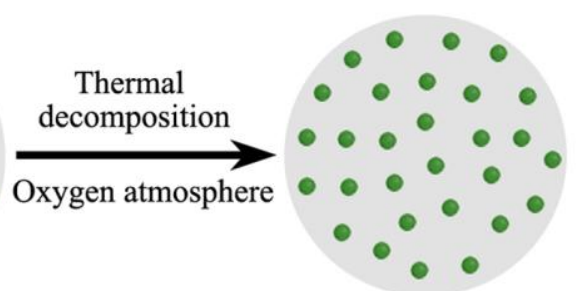

$\mathrm{NiO}$ nanodots suspending in hexane

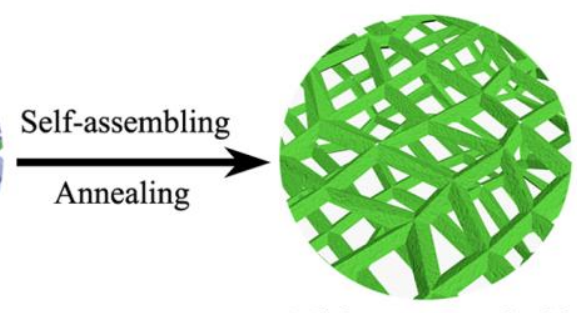

Ni foam covered with self-assembled $\mathrm{NiO}$

Figure 1. Schematic illustration of (a) the monodisperse $3 \mathrm{~nm} \mathrm{NiO}$ nanodot preparation and (b) the self-assembly of $3 \mathrm{~nm} \mathrm{NiO}$ nanodots on macroporous Ni foam.

Figure 1 presents the basic concept underpinning the synthesis and self-assembly of the $\mathrm{NiO}$ nanodots. To obtain monodisperse $3 \mathrm{~nm}$ NiO nanodots, a modified high-temperature solution-phase technology is used under an oxygen atmosphere (Figure 1a). [20, 21] Conventionally, discrete metal-oxide nanodots are produced by sputtered metal atoms in a cluster gun under oxygen gas chamber. [23, 24] Alternatively, direct synthesis via solution-phase reaction offers a simple, low-cost, scalable and well-controlled production strategy. [20-22, 25] Typically, $1 \mathrm{~g}$ nickel(acetylacetonate $)_{2}\left[\mathrm{Ni}(\mathrm{acac})_{2}\right]$ and $8 \mathrm{~g}$ oleylamine are mixed at $100{ }^{\circ} \mathrm{C}$ under an oxygen atmosphere. The resulting solution is rapidly heated to $200{ }^{\circ} \mathrm{C}$ and kept at this temperature for 30 min until its color changes from dark-green to yellow-brown, indicating successful synthesis of 3 $\mathrm{nm} \mathrm{NiO}$ nanodots (Figure $\mathrm{S} 1$ ). The as-synthesized $\mathrm{NiO}$ nanodots can be stably dispersed in hexane without precipitation for several months (Figure S2). Self-assembly of $3 \mathrm{~nm} \mathrm{NiO}$ nanodots on 
macroporous $\mathrm{NF}$ (designated as $3 \mathrm{~nm} \mathrm{NiO/NF)} \mathrm{or} \mathrm{copper} \mathrm{foil} \mathrm{(designated} \mathrm{as} 3 \mathrm{~nm} \mathrm{NiO/CF}$ ) is achieved via immersing the substrates into $\mathrm{NiO}$ nanodot-hexane dispersions, followed by evaporation at room-temperature and pressure (Figure $1 \mathrm{~b}$, see details in experiment section). During evaporation of hexane, $\mathrm{NiO}$ nanodots self-assemble via van der Waals forces and tightly adhere to the NF framework after further annealing and degassing. [19, 26] The metallic silver-gray NF becomes dark and the coppery color of CF becomes gray after the self-assembly of $\mathrm{NiO}$ nanodots (Figure S3). As a comparison, $30 \mathrm{~nm} \mathrm{NiO}$ nanoparticles (designated as $30 \mathrm{~nm} \mathrm{NiO/NF}$ ) are also synthesized and self-assembled on NF (See experimental section for details). X-ray diffraction (XRD) patterns on both NF and CF substrates display the three main peaks for the (111), (200) and (220) planes of cubic NiO (JCPDS 78-0643), indicating a self-assembly of randomly orientated 3 nm NiO nanodots (Figure S4).

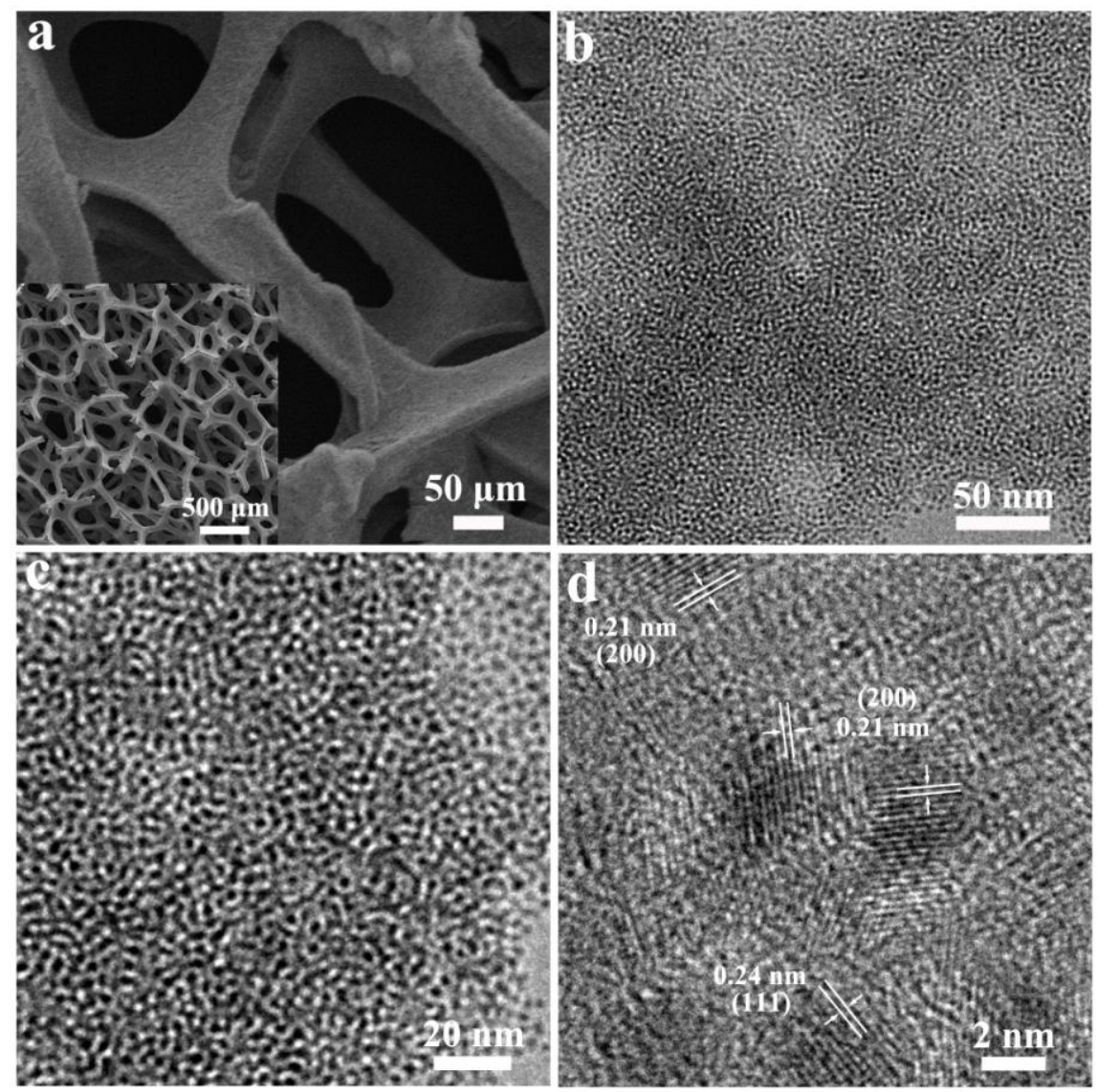

Figure 2. (a) High- and low-magnification (inset) SEM images and (b-d) TEM images at different magnifications of self-assembled $3 \mathrm{~nm} \mathrm{NiO}$ on $\mathrm{NF}$.

Scanning electron microscopy (SEM) and transmission electron microscopy (TEM) reveal more information on the self-assembled $\mathrm{NiO}$ nanodots on the surface of the 3D macroporous NF (Figure 2). Low-magnification SEM (Figure 2a inset) demonstrates that the 3D interconnected 
metal backbones of the macroporous networks, which could provide highly efficient path for fast electron transport and high electrochemical utilization of the $\mathrm{NiO}$ nanodots. Figure 2a shows that the macroporous skeletons of NF are conformably covered with mesoporous nanostructure assembled by $\mathrm{NiO}$ nanodots. SEM images of $3 \mathrm{~nm} \mathrm{NiO} / \mathrm{NF}$ at different magnification are further presented in Figure S5a-c. The TEM image of the NiO nanodots scraped from macroporous NF reveals that a large number of uniform nanodots tightly interconnect with each other to form wormlike channels (Figure $2 \mathrm{~b}$ ) as a result of the randomly-packed self-assembly. These nanochannels between the nanodots clearly show mesopore size ranging from 5 to $10 \mathrm{~nm}$ (Figure 2c). The HRTEM lattice fringe image presented in Figure $2 \mathrm{~d}$ reveals that the size of the NiO nanodots is $\sim 3 \mathrm{~nm}$, indicating a high surface area. Nitrogen adsorption-desorption isotherm further demonstrates a narrow mean size $\sim 7 \mathrm{~nm}$ (Figure S5), in agreement with the TEM observation. The BET surface area of $3 \mathrm{~nm} \mathrm{NiO}$ nanodots is $\sim 268 \mathrm{~m}^{2} \mathrm{~g}^{-1}$, much higher than that of the bulk $\mathrm{NiO}(\sim 3$ $\left.\mathrm{m}^{2} \mathrm{~g}^{-1}\right)$. As a comparison, $30 \mathrm{~nm} \mathrm{NiO}$ nanoparticles demonstrate a BET surface area of $\sim 22 \mathrm{~m}^{2} \mathrm{~g}^{-1}$ and wormlike nanochannels $\sim 10 \mathrm{~nm}$ after self-assembling (Figure S6). This 3D interconnected macro-mesoporous $3 \mathrm{~nm}$ NiO/NF nanostructure with high surface area can highly facilitate the access of electrolyte to the active materials. [13,27]

To show its high rate behavior for supercapacitor-like LIBs, the characteristic rate performance of supercapacitor using our $3 \mathrm{~nm} \mathrm{NiO/NF}$ electrode is first measured (Figure 3). Cyclic voltammetry $(\mathrm{CV})$ curves exhibit a strong oxidation peak and a sharp reduction peak instead of the rectangular shape. We attribute this to the pseudocapacitance of the $\mathrm{NiO}$ nanostructure. The anodic peak $\sim 0.31 \mathrm{~V}$ is related to the surface oxidation of $\mathrm{NiO}$ to $\mathrm{NiOOH}\left(\mathrm{NiO}+\mathrm{OH}^{-} \leftrightarrow \mathrm{NiOOH}+\mathrm{e}^{-}\right)$. The cathodic peak at $\sim 0.21 \mathrm{~V}$ is its reverse process. [28] The high-power characteristic of supercapacitor can be identified from the voltammetric response at various scan rates from 10 to $100 \mathrm{mV} \mathrm{s}^{-1}$. [16] Obviously, all curves exhibit similar redox shapes and the current density increases with the increasing scan rate. Even at a high scan rate of $100 \mathrm{mV} \mathrm{s}^{-1}$, the $\mathrm{CV}$ curve still shows a pair of redox peaks. As the charge storage occurs at the surface layer of the nanostructures immersed in electrolyte, a fast redox action delivering energy at ultra-high rate can be achieved for the electrodes due to interconnected porous network to facilitate highly efficient transfer of the $\mathrm{OH}^{-}$ions. [4, 27] The specific capacitance values of $30 \mathrm{~nm} \mathrm{NiO/NF}$ electrode at the current densities of 2, 5, 10, 20 and $50 \mathrm{~A} \mathrm{~g}^{-1}$ are 162, 149, 132, 113 and $90 \mathrm{~F} \mathrm{~g}^{-1}$, respectively. The effect of particle-size on the 
performance of $\mathrm{NiO}$ nanparticles in supercapacitor was previously studied and showed that the particle size of the $\mathrm{NiO}$ nanostructure plays an important role because of the presence of a higher number of active sites for a faradaic reaction. [29] The $3 \mathrm{~nm} \mathrm{NiO} / \mathrm{NF}$ electrode has higher specific surface area for $\mathrm{OH}^{-}$ion adsorption reaction as seen from the larger area of the enclosed $\mathrm{CV}$ curve (Figure S7). Thus, the specific capacitance values of the $3 \mathrm{~nm} \mathrm{NiO/NF}$ electrode at the same current densities are strongly increased to 856, 823, 806, 778 and $702 \mathrm{~F} \mathrm{~g}^{-1}$, respectively (Figure 3a), showing as high as $82 \%$ capacitance retention. Our capacitances and rate performances are also among the highest in recent literatures reported for $\mathrm{NiO}$ materials. [30-34] As supercapacitors only store charges at surface or in thin-layer region of active materials and almost involve no ion diffusion in the bulk of materials, [4] the mesoporous nanostructure self-assembled by $3 \mathrm{~nm} \mathrm{NiO}$ nanodots on conductive macroporous NF herein demonstrates an outstanding electrode architecture, which could enable rapid ion transfer in the 3D interconnected electrolyte-filled macro-mesoporous networks. After 10,000 cycles, the 3nm NiO/NF electrode exhibits high capacitance retention of $93 \%$ at a current density of $2 \mathrm{~A} \mathrm{~g}^{-1}$ (Figure 3b), revealing the long-term charging-discharging stability of these electrodes for electrochemical supercapacitor.
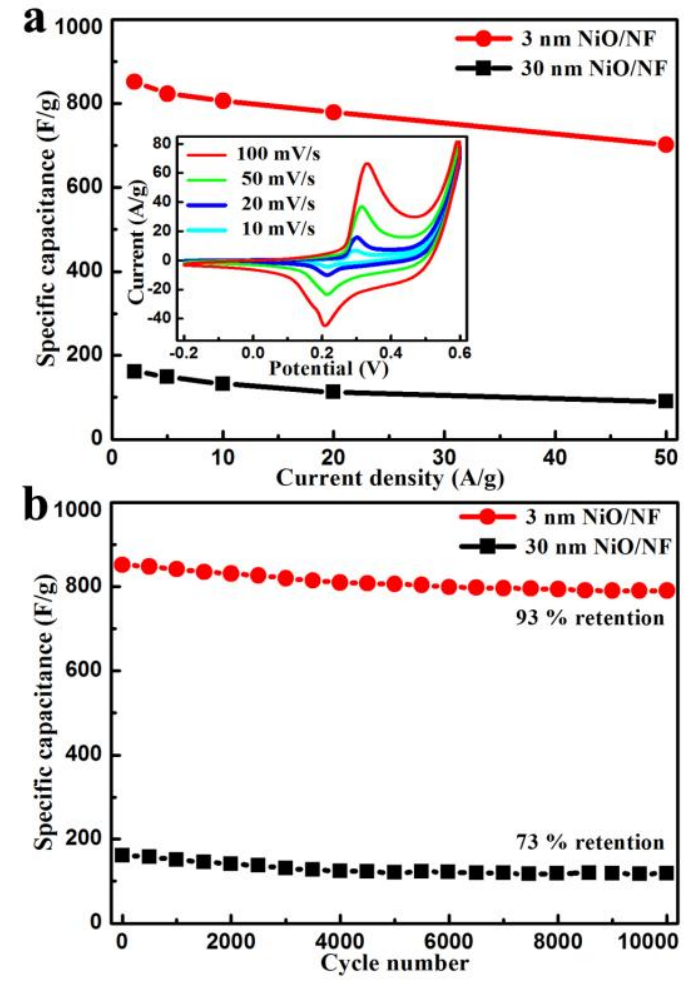

Figure 3. (a) The specific capacitances as a function of current density and (b) cycling stability at $2 \mathrm{~A} \mathrm{~g}^{-1}$ of $3 \mathrm{~nm}$ $\mathrm{NiO} / \mathrm{NF}$ and $30 \mathrm{~nm} \mathrm{NiO/NF}$ as electrodes for supercapacitor. The inset in (a) shows the cyclic voltammetry curves of $3 \mathrm{~nm} \mathrm{NiO/NF}$ at various scan rates. 
The Li-storage performances of self-assembled $\mathrm{NiO}$ nanodots and nanoparticles on $\mathrm{NF}$ substrate as a free-standing binder-free working electrode are next evaluated (Figure 4). The discharge-charge voltage profiles of the $3 \mathrm{~nm} \mathrm{NiO/NF}$ electrode (Figure $4 \mathrm{a}$ inset) exhibit obvious discharge plateau at $\sim 0.7 \mathrm{~V}$ and sloping charge plateau at $\sim 1.2 \mathrm{~V}$, responsible for the reversible conversion reaction: $\mathrm{NiO}+2 \mathrm{Li}^{+}+2 \mathrm{e} \leftrightarrow \mathrm{Ni}+\mathrm{Li}_{2} \mathrm{O}$. [23, 35] The $3 \mathrm{~nm} \mathrm{NiO/NF}$ electrode delivers a discharge capacity of $1045 \mathrm{~mA} \mathrm{~h} \mathrm{~g}^{-1}$ at the first cycle, which exceeds the theoretical capacity of $\mathrm{NiO}$ bulk (718 $\mathrm{mA} \mathrm{h} \mathrm{g}^{-1}$ for $2 \mathrm{Li}^{+}$per $\left.\mathrm{NiO}\right)$. The additional capacity can be attributed to the nanoscale interfacial Li-storage, due to the highly increased surface area of such small-sized nanodots. [36] However, the interfacial Li-storage is partly unstable or irreversible during the cycling. We believe that at the fifth cycle, the capacity decreases to $747 \mathrm{~mA} \mathrm{~h} \mathrm{~g}^{-1}$ due to this. Still, the $3 \mathrm{~nm} \mathrm{NiO} / \mathrm{NF}$ electrode exhibits a long-life cycling stability up to 1000 cycles with a reversible capacity of 710 $\mathrm{mA} \mathrm{h} \mathrm{g}^{-1}$ at a current density of $1 \mathrm{~A} \mathrm{~g}^{-1}$ (Figure 4a). It is well known that the reversible lithiation and delithiation occurring in the bulk of a material via Li-ions solid-state diffusion can extensively pulverize larger particles into smaller particles of less than $\sim 10 \mathrm{~nm}$, resulting in poor cycle-stability or low capacity retention.[11, 23, 37] However, this pulverizing phenomenon is not observed in our $3 \mathrm{~nm} \mathrm{NiO/NF}$ electrode. The TEM image (Figure 4a inset) clearly reveals that the nanodot size and the self-assembled mesoporous structure are well maintained after 500 cycles, suggesting the high cycle-stability of $3 \mathrm{~nm} \mathrm{NiO/NF}$ electrode. [12, 36]

As mentioned above, the characteristic time for Li-ion diffusion through an active material decreases with the square of characteristic size of the active materials. [3, 12,13] With rapid ion transfer through the entire electrode architecture containing both ultra-short-range solid-state and macro-mesoporous electrolyte-filled networks, considerable Li-storage capacity could be achieved even under ultrahigh rate. [13, 27] The rate capabilities of $3 \mathrm{~nm}$ NiO/NF, $30 \mathrm{~nm}$ NiO/NF (Figure S6) and $3 \mathrm{~nm} \mathrm{NiO/CF}$ electrodes (Figure S8) are employed as a comparison. The $3 \mathrm{~nm} \mathrm{NiO/CF}$ electrode shows no macro-mesoporous networks. Remarkably, the $3 \mathrm{~nm}$ NiO/NF electrode exhibits much higher rate capability than both $30 \mathrm{~nm} \mathrm{NiO/NF}$ and $3 \mathrm{~nm} \mathrm{NiO/CF}$ electrodes (Figure 4b). The specific capacities of the $3 \mathrm{~nm} \mathrm{NiO/NF}$ electrode at increasing current densities of 2, 5, 10 and $20 \mathrm{~A}$ $\mathrm{g}^{-1}$ are $685,660,635$ and $603 \mathrm{~mA} \mathrm{~h} \mathrm{~g}^{-1}$, respectively. The electrochemical impedances for $3 \mathrm{~nm}$ $\mathrm{NiO} / \mathrm{NF}, 30 \mathrm{~nm} \mathrm{NiO/NF}$ and $3 \mathrm{~nm} \mathrm{NiO/CF}$ electrodes were also measured as shown in Figure 4c. The arc in the high frequency region corresponds to the charge transfer resistance. The impedance 
resistances of three samples are $\sim 10 \Omega, 14 \Omega$, and $43 \Omega$, respectively. And the straight line in the low frequency region is ascribed to the diffusive resistance related to the diffusion of $\mathrm{Li}$-ion in the electrode. The electrochemical impedance spectra (EIS) results verify that the $3 \mathrm{~nm} \mathrm{NiO/NF}$ electrode architecture exhibits the lowest internal resistance among the three electrodes, showing that the charge transfer throughout the electrode can also be effective enough to accommodate ultrahigh rate due to the closely-packed assembly of $3 \mathrm{~nm} \mathrm{NiO}$. [14, 17] The $3 \mathrm{~nm} \mathrm{NiO/CF}$ presents a much higher impedance resistance, indicating its low conductivity and its low charge transfer capability.
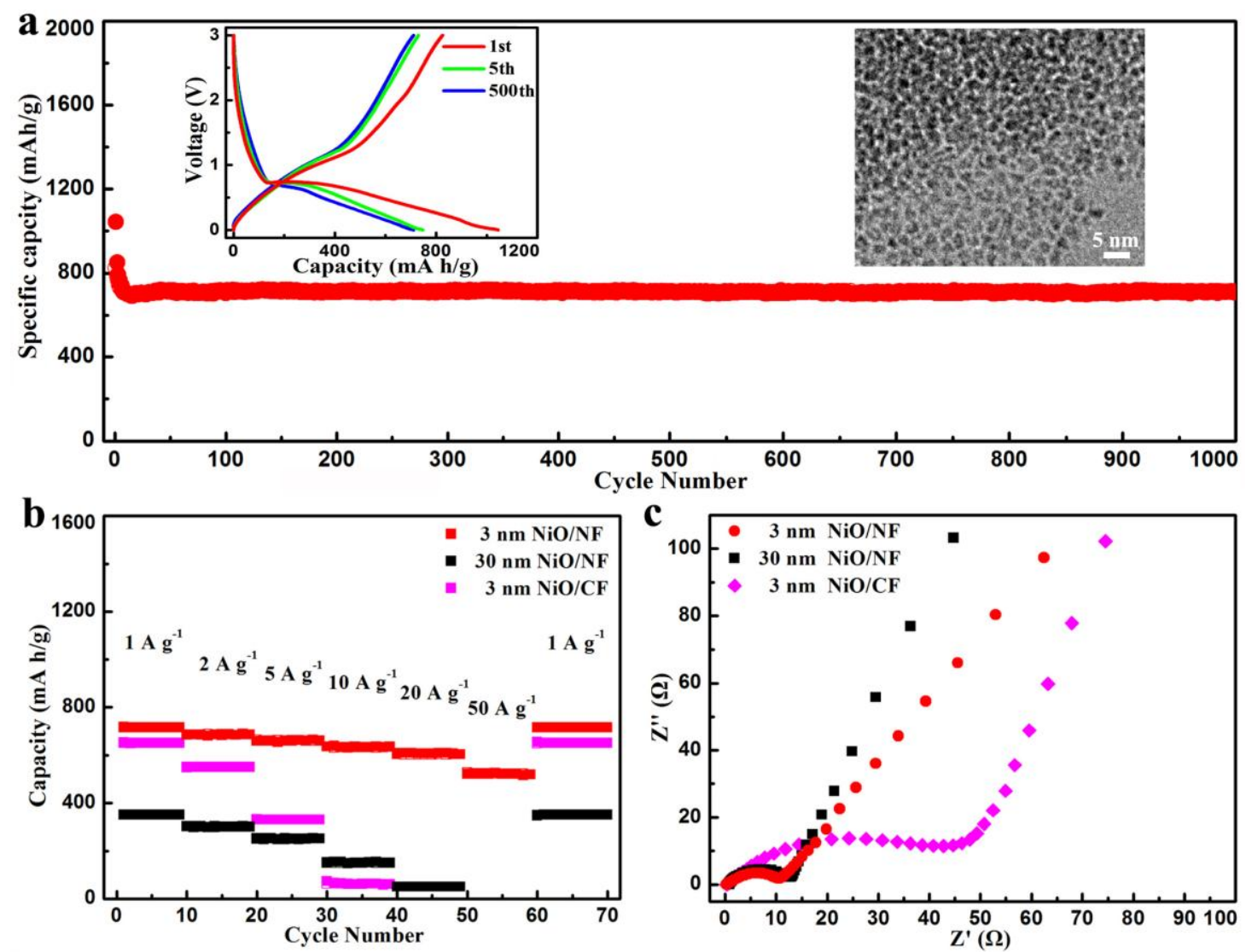

Figure 4. (a) The specific capacity of the $3 \mathrm{~nm} \mathrm{NiO/NF}$ for Li-ion battery at $1 \mathrm{~A} \mathrm{~g}^{-1}$ for 1000 cycles; (b) Rate capabilities and (c) electrochemical impedances for $3 \mathrm{~nm} \mathrm{NiO/NF,} 30 \mathrm{~nm} \mathrm{NiO/NF}$ and $3 \mathrm{~nm} \mathrm{NiO/CF}$ electrodes, respectively. The inset plots in (a) show the 1, 5, and 500 charge-discharge curves. The second inset in (a) is a TEM image, revealing unaltered particle shape, size and mesoporous structure of $3 \mathrm{~nm} \mathrm{NiO/NF}$ after 500 cycles at $1 \mathrm{Ag}^{-1}$.

The achieved rate performance of $3 \mathrm{~nm} \mathrm{NiO/NF}$ as the working electrode for Li-ion battery (Figure 5a) is even comparable to that of the supercapacitor (Figure 3a), demonstrating a supercapacitor-like rate performance. Compared to advanced anode materials recently reported with high rate capability, the capacity retention of $3 \mathrm{~nm} \mathrm{NiO} / \mathrm{NF}$ is $89 \%, \sim 2$ times higher than those of 
nitrogen-doped porous carbon and $\sim 8 \mathrm{~nm} \mathrm{SnO}_{2}$ electrodes respectively, where the capacity retention is only $40 \%$ and $35 \%$ when the current increased from 1 to $10 \mathrm{Ag}^{-1}$. [37, 38] Even at extremely high current density of $50 \mathrm{~A} \mathrm{~g}^{-1}$ (a 50 fold increase in discharge current), the battery with $3 \mathrm{~nm} \mathrm{NiO} / \mathrm{NF}$ electrode delivers a reversible capacity of $518 \mathrm{~mA} \mathrm{~h} \mathrm{~g}^{-1}$ with $73 \%$ capacity retention. Our $3 \mathrm{~nm}$ $\mathrm{NiO} / \mathrm{NF}$ electrode also demonstrate the best rate capability, cycling properties and charge-discharge capacity among the $\mathrm{NiO}$ materials reported recently. [39-42] Figure 5b illustrates Ragone plot to describe the relation between energy density and power density of the samples. Our Li-ion battery with $3 \mathrm{~nm} \mathrm{NiO} / \mathrm{NF}$ displays high power density of $\sim 0.7 \mathrm{~kW} \mathrm{~kg}^{-1}$ at an energy density of $\sim 490 \mathrm{Wh}$ $\mathrm{kg}^{-1}$, approaching to the low end for power densities of supercapacitors (1-10 $\left.\mathrm{kW} \mathrm{kg}^{-1}\right)$. At higher power density near $1.4,3.5,7$ and $14 \mathrm{~kW} \mathrm{~kg}^{-1}$, the energy density is $\sim 480,460,440$ and $420 \mathrm{Wh}$ $\mathrm{kg}^{-1}$, respectively, bridging the performance gap between normal supercapacitors and batteries. [43] The battery exhibits a higher power density of $\sim 35 \mathrm{~kW} \mathrm{~kg}^{-1}$ with energy density as high as $\sim 360 \mathrm{Wh}$ $\mathrm{kg}^{-1}$, far superior to that of typical supercapacitors (1-10 $\left.\mathrm{Wh} \mathrm{kg}^{-1}\right)$ at the same power level. It is also evident that the energy densities achieved here are higher than that of the upper end of traditional Li-ion batteries. The poor performance observed for $3 \mathrm{~nm} \mathrm{NiO} / \mathrm{CF}$ electrode is due to the lack of the meso-macroporous structures of copper foils; showing the importance of the presence of 3D meso-macroporous architecture for rapid charge transfer and ion diffusion. The mass loading of our $3 \mathrm{~nm} \mathrm{NiO} / \mathrm{NF}$ is $3.6 \mathrm{mg} \mathrm{cm}^{-2}$. The capacity is $\sim 710-1045 \mathrm{~mA} \mathrm{~h} \mathrm{~g}^{-1}$, which corresponds to a capacity loading as high as $\sim 2.6-3.8 \mathrm{mAh} \mathrm{cm}^{-2}$. This is comparable to the state-of-the-art capacity loading of 2.0-3.5 mAh/cm $\mathrm{cm}^{2}$. Furthermore, the as-obtained reversible capacity of $518 \mathrm{~mA} \mathrm{~h} \mathrm{~g}^{-1}$ at $50 \mathrm{~A} \mathrm{~g}^{-1}$ exceeds $\sim 10$ times than that of the state-of-art graphite anode, which shows only $\sim 50 \mathrm{~mA} \mathrm{~h} \mathrm{~g}^{-1}$ at 2-3 $\mathrm{A} \mathrm{g}^{-1}$ as anode for Li-ion battery. [8] This result would promote further development of higher performance supercapacitor-like Li-ion full-cells in the near future. However, it is very difficult to get high-performace cathode material as standard reference to evaluate the performance of full-cells. Since, similar supercapacitor-like working performance can be obtained from very few of cathode materials, such as nano-sized $\mathrm{LiFePO}_{4}$ and lithiated $\mathrm{MnO}_{2}$. And these cathode materials possess relatively low energy density of $\sim 20-100 \mathrm{Wh} \mathrm{kg}^{-1}$. [2, 3] These cathode materials need also further optimization and developement. We are working on the full cell device.

High-performance electrode requires the simultaneous optimization of the primary transfer process during charge and discharge (Figure 5c): (1) ion transfer in the electrolyte, (2) ion diffusion 
in the electrode, (3) electron conduction in the electrode and current collector. We propose that the high electrochemical performance of $3 \mathrm{~nm} \mathrm{NiO/CF}$ comes from the unique 3D interconnected macro-mesoporous networks with high surface-area. $[3,12,13]$ We demonstrated that this electrode architecture simultaneously provides excellent electron conduction form metal $\mathrm{Ni}$, rapid ion transfer in electrolyte-filled macro-mesoporous network, and ultra-short solid-phase ion diffusion. We believe that this general material design principle and significant progress we demonstrate here on 3 $\mathrm{nm} \mathrm{NiO} / \mathrm{NF}$ anode material could be used for further development of higher-performance supercapacitor-like Li-ion full-cell in the near future.

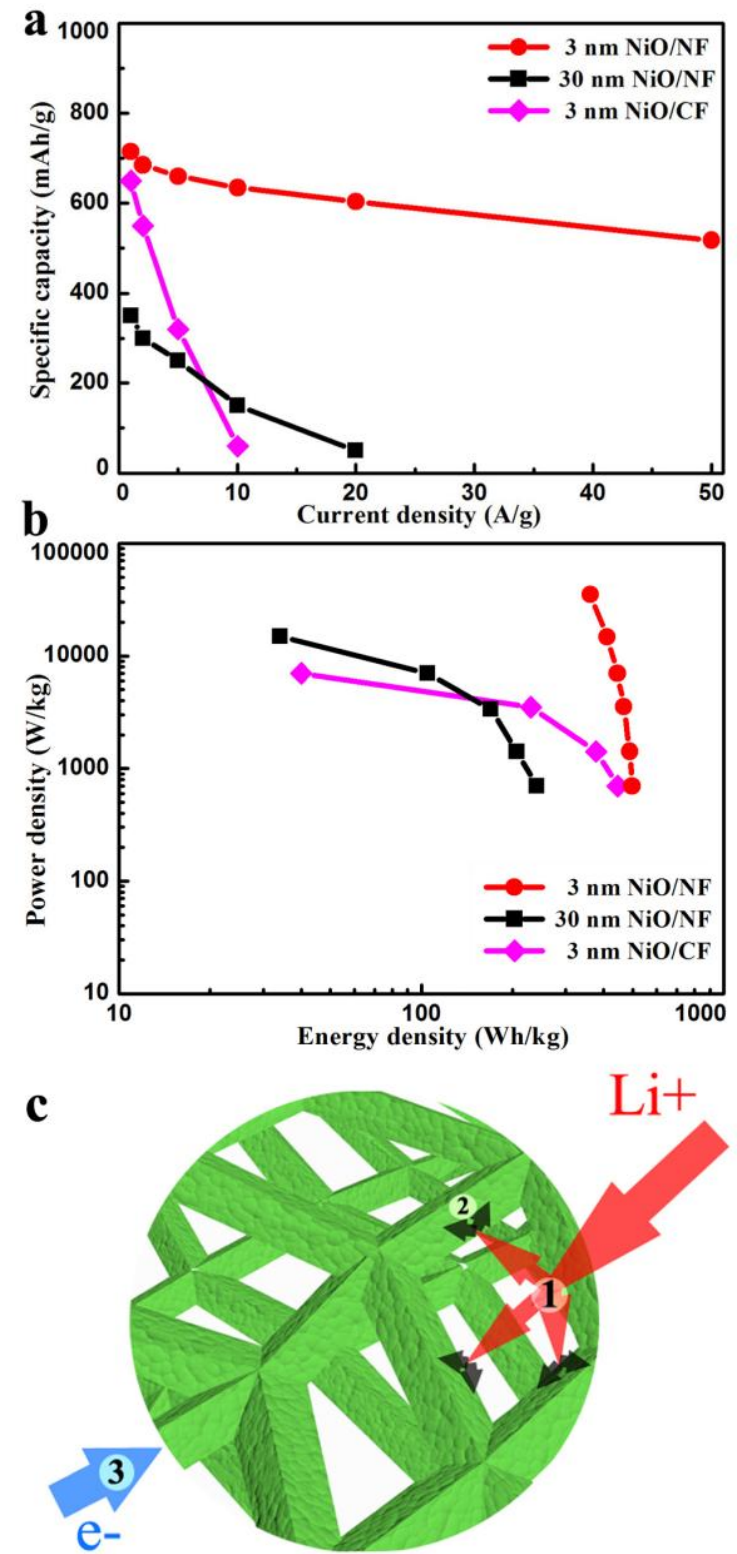

Figure 5. (a) The specific capacity as a function of current density for $3 \mathrm{~nm} \mathrm{NiO} / \mathrm{NF}, 30 \mathrm{~nm} \mathrm{NiO} / \mathrm{NF}$ and $3 \mathrm{~nm}$ $\mathrm{NiO} / \mathrm{CF}$; (b) Ragone plots of the Li-ion batteries using different NiO samples; (c) Illustration of the Li-ion transfer in the electrolyte and electrode, and electron conduction in the electrode for our $\mathrm{Li}$-ion batteries. 


\section{Conclusion}

We demonstrated a facile approach to fabricate a binder-free macro-mesoporous electrode via self-assembly of $3 \mathrm{~nm} \mathrm{NiO}$ nanodots on macroporous nickel foam for high-performance supercapacitor-like Li-ion battery. The as-prepared electrode possesses high surface-area and 3D interconnected macro-mesoporous networks, facilitating rapid ion transfer in electrolyte and ultra-short solid-phase ion diffusion. This unique architecture enables Li-ion storage battery devices working with supercapacitor rate capabilities while maintaining high battery capacities. Our strategy paves a new way to fabricate free-standing binder-free electrode for high-performance electrochemical energy storage devices and is a significant step towards the development of the ultimate power source for next generation electric vehicles.

\section{Acknowledgements}

This work was financially supported by Chinese Ministry of Education in a framework of the Changjiang Scholar Innovative Research Team Program (IRT_15R52). This work is also supported by International Science \& Technology Cooperation Program of China (2015DFE52870), Chinese Ministry of Education with a PhD Programs Foundation (20120143120019), Hubei Provincial Natural Science Foundation (2014CFB160), the National Science Foundation for Young Scholars of China (No. 51302204) and the Royal Academy of Engineering through a Fellowship (Graphlex). The authors also thank J. L. Xie, X. Q. Liu and T. T. Luo for TEM analysis from the Research and Test Center of Materials at Wuhan University of Technology.

\section{Appendix A. Supporting Information}

Materials characterizations and electrochemical characterizations.

\section{References}

[1] A. S. Aricò, P. Bruce, B. Scrosati, J. M. Tarascon, W. V. Schalkwijk, Nat. Mater. 4 (2005) 366-377.

[2]B. Kang , G. Ceder, Nature 458 (2009) 190-193.

[3]H. Zhang, X. Yu, P. V. Braun, Nat. Nanotech. 6 (2011) 277-281. 
[4]J. Jiang, Y. Li, J. Liu, X. Huang, C. Yuan, X. W. Lou, Adv. Mater. 24 (2012) 5166-5180.

[5]Z. Gao, N. Song, X. Li, J. Mater. Chem. A, 3 (2015), 14833-14844.

[6] Z. Gao, W. Yang, J. Wang, N. Song, X. Li, Nano Energy 13 (2015) 306-317.

[7]M. V. Reddy, G. V. Subba Rao, B. V. R. Chowdari, Chem. Rev. 113 (2013) 5364-5457.

[8]A. Magasinski, P. Dixon, B. Hertzberg, A. Kvit, J. Ayala, G. Yushin, Nat. Mater. 9 (2010) 353-358.

[9]Y. Li, Z.Y. Fu, B. L. Su, Adv. Funct. Mater. 22 (2012) 4634-4667.

[10] D. Kong, J. Luo, Y. Wang, W. Ren, T. Yu, Y, Luo, Y. Yang, C. Cheng, Adv. Funct. Mater. 24 (2014) 3815-3826.

[11] D. H. Ha, M. A. Islam, R. D. Robinson, Nano Lett. 12 (2012) 5122-5130.

[12]Y. G. Guo, J. S. Hu, L. J. Wan, Adv. Mater. 20 (2008) 2878-2887.

[13]A. Vu, Y. Qian, A. Stein, Adv. Energy Mater. 2 (2012) 1056-1085.

[14]N. Feng, D. Hu, P. Wang, X. Sun, X. Li, D. He, Phys. Chem. Chem. Phys. 15 (2013) 9924-9930.

[15]C. Guan, X. Li, Z. Wang, X. Cao, C. Soci, H, Zhang, H. J. Fan, Adv. Mater. 24 (2012) 4186-4190.

[16]G. Zhang, X. W. Lou, Adv. Mater. 25 (2013) 976-979.

[17]X. Huang, H. Yu, J. Chen, Z. Lu, R. Yazami, H. H. Hng, Adv. Mater. 26 (2014)1296-1303.

[18]Z. Nie, A. Petukhova, E. Kumacheva, Nat. Nanotech. 5 (2010) 15-25.

[19]J. Lee, S. Zhang, S. Sun, Chem. Mater. 25 (2013) 1293-1304.

[20]X. Zheng, S. Yuan, Z. Tian, S. Yin, J. He, K. Liu, L. Liu, Mater. Lett. 63 (2009) 2283-2285.

[21]X. Zheng, S. Yuan, Z. Tian, S. Yin, J. He, K. Liu, L. Liu, Chem. Mater. 21 (2009) 4839-4845.

[22]X. Zheng, G. Shen, Y. Li, H. Duan, X. Yang, S. Huang, H. Wang, C. Wang, Z. Deng, B. L. Su, J. Mater. Chem. A 1 (2013) 1394-1400.

[23]B. Varghese, M. V. Reddy, Z. Yanwu, C. S. Lit, T. C. Hoong, G. V. S. Rao, B. V. R. Chowdari, A. T. S. Wee, C. T. Lim, C. H. Sow, Chem. Mater. 20 (2008) 3360-3367.

[24]V. Skumryev, S. Stoyanov, Y. Zhang, G. Hadjipanayis, D. Givord, J. Nogués, Nature 423 (2003) 850-853.

[25]Y. Li, X. Y. Yang, Y. Feng, Z. Y. Yuan, B. L. Su, Crit. Rev. Solid State Mat. Sci. 37 (2012) $1-74$. 
[26]Z. Nie, A. Petukhova, E. Kumacheva, Nat. Nanotech. 5 (2010) 15-25.

[27]S. Chabi, C. Peng, D. Hu, Y. Zhu, Adv. Mater. 26 (2014) 2440-2445.

[28]C. Wu, S. Deng, H. Wang, Y. Sun, J. Liu, H, Yan, ACS Appl. Mater. Interfaces 6 (2014) 1106-1112.

[29]S. P. Jahromi, A. Pandikumar, B. T. Goh, Y. S. Lim, W. J. Basirun, H. N. Lim, N. M. Huang, RSC Adv., 2015, 5, 14010

[30]F. I. Dar, K. R. Moonooswarmy, M. Es-Souni, Nanoscale Res. Lett. 8 (2013) 363.

[31]K. Liang, X. Tang, W. Hu, J. Mater. Chem. 22 (2012) 11062.

[32]F. Cao, G. X. Pan, X. H. Xia, P. S. Tang, H. F. Chen, Journal of Power Sources 264 (2014) 161-167.

[33]Q. Lu, M. W. Lattanzi, Y. Chen, X. Kou, W. Li, X. Fan, K. M. Unruh, J. G. Chen, J. Q. Xiao, Angew. Chem. Int. Ed. 50 (2011) 6847-6850.

[34]H. Yan, D. Zhang, J. Xu, Y. Lu, Y. Liu, K. Qiu, Y. Zhang, Y. Luo, Nanoscale Res. Lett. 9 (2014) 424.

[35]J. H. Pan, Q. Huang, Z. Y. Koh, D. Neo, X. Z. Wang, Q. Wang, ACS Appl. Mater. Interfaces 5 (2013) 6292-6299.

[36]S. J. Yang, S. Nam, T. Kim, J. H. Im, H. Jung, J. H. Kang, S. Wi, B. Park, C. R. Park, J. Am. Chem. Soc. 135 (2013) 7394-7397.

[37]J. M. Haag, G. Pattanaik, M. F. Durstock, Adv. Mater. 25 (2013) 3238-3243.

[38]L. Qie, W. M. Chen, Z. H. Wang, Q. G. Shao, X. Li, L. X. Yuan, X. L. Hu, W. X. Zhang, Y. H. Huang, Adv. Mater. 24 (2012) 2047-2050.

[39]H. Liu, G. Wang, J. Liu, S. Qiao, H. Ahn, J. Mater. Chem., 21 (2011) 3046.

[40]X. Wang, X. Li, X. Sun, F. Li, Q. Liu, Q. Wang, D. He, J. Mater. Chem., 21 (2011) 3571.

[41]V. Aravindan, P. S. Kumar, J. Sundaramurthy, W. C. Ling, S. Ramakrishna, S. Madhavi, Journal of Power Sources 227 (2013) 284-290.

[42]A. Caballero, L. Hernán, J. Morales, Z. González, A. J. Sánchez-Herencia, B. Ferrari, Energy Fuels 27 (2013) 5545-5551.

[43]C. Zhou, Y. Zhang, Y. Li, J. Liu, Nano Lett. 13 (2013) 2078-2085. 


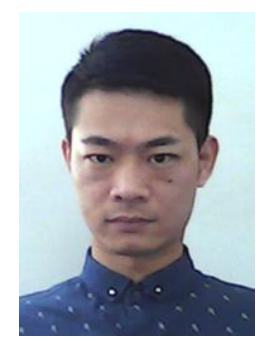

Xianfeng Zheng received his Ph.D. in Material Physics and Chemistry from Huazhong University of Science and Technology in 2010. Then, he started his postdoctoral researches at Wuhan University of Technology with Prof. Bao-Lian Su on hierarchically structured porous nanomaterials. Currently, he is an Assistant Professor in State Key Laboratory of Advanced Technology for Materials Synthesis and Processing from Wuhan University of Technology. His research interest is aimed at the bio-inspired design, synthesis and self-assembly of nanoparticles towards new nanomaterials with hierarchical porosity for energy and environment.

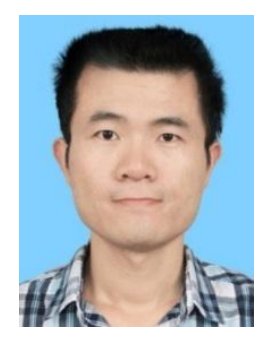

Hongen Wang received his Bachelor degree at Central South University in 2007 and $\mathrm{Ph}$. D degree at City University of Hong Kong in 2012. He is now an Associate Professor in the Laboratory of Living Materials from the Wuhan University of Technology in 2012 and Postdoctoral Research Assistant in Physics and Materials Science at the City University of Hong Kong. His interests are mainly focused on the synthesis and applications of functional materials in the field of energy conversion and storage.

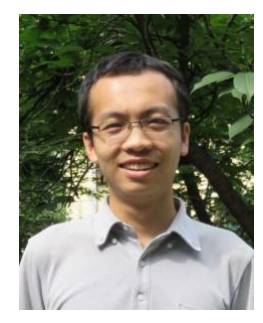

Chao Wang obtained his Master of Engineering degree in 2013 from Wuhan University of Technology, China. He is pursuing his Ph.D. degree under the guidance of Prof. Bao-Lian Su and 
Prof. Yu Li in Laboratory of Living Materials at State Key Laboratory of Advanced Technology for Materials Synthesis and Processing, Wuhan University of Technology, China. His current research involves developing techniques for advanced microscopy and the synthesis of organic-inorganic metal sulfide nanomaterials for photocatalysis applications and their antiphotocorrosion mechanism.

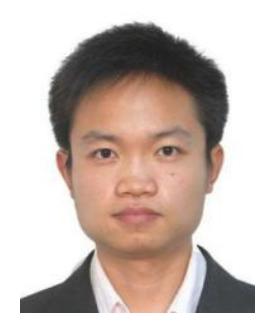

Zhao Deng received his B.S. and Ph.D. from Wuhan University of technology in 2005 and 2010. He worked as visiting scholar in CMI at the Universityof Namur with Prof. Bao-Lian Su in 2011. Currently, he works in Wuhan University of Technology. His research interests are synthesis of functional nanomaterials and their applications in catalysis, environmental protection and other fields.

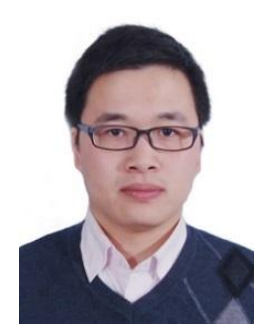

Lihua Chen awarded his Ph.D degrees, one in inorganic chemistry from Jilin University, China (2009), and another in inorganic materials chemistry from University of Namur, FUNDP, Belgium (2011). In 2011-2012, he held a project-researcher position at the University of Namur with Professor Bao-Lian Su working on hierarchically porous zeolites. He is currently a full professor working in the State Key Laboratory of Advanced Technology for Materials Synthesis and Processing from the Wuhan University of Technology, China. His research is aimed at new porous materials with designed hierarchically porosity towards catalysis. 


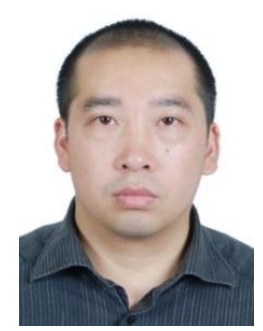

Yu Li received his B.S. from Xi'an Jiaotong University in 1999 and received his M.S. from Liaoning Shihua University in 2002. He obtained his Ph.D. from Zhejiang University in 2005. He worked in EMAT at the University of Antwerp with Prof. G. Van Tendeloo in 2005 and then in CMI at the University of Namur with Prof. Bao-Lian Su in 2006. Currently, he is a "Chutian" professor at Wuhan University of Technology. His research interests include nanomaterials design and synthesis, hierarchically porous materials synthesis, and their applications in the fundamental aspects of energy and environment.

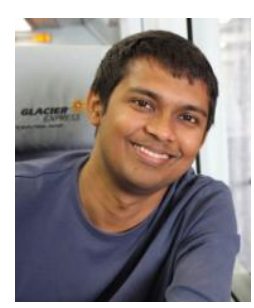

Tawfique Hasan gained his $\mathrm{PhD}$ from the University of Cambridge in 2009. He is currently a University Lecturer in Electronic Materials and Devices, Deputy Director for Teaching and Training of the EPSRC funded Centre for Doctoral Training in Graphene Technology and Director of the MRes program in Graphene Technology at the Cambridge Graphene Centre, Cambridge University Engineering Department. Hasan's current research focuses on formulation of functional inks of 0, 1and 2-dimensional nanomaterials and their hybrids for a wide range of printable and flexible device applications including ultrafast lasers, photonic, (opto)electronic and energy devices. He is a Title A Fellow of Churchill College, Cambridge and currently holds a prestigious Royal Academy of Engineering Research Fellowship. 


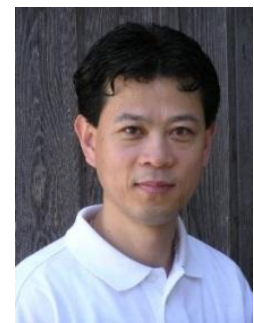

Prof. Bao-Lian Su created the Laboratory of Inorganic Materials Chemistry (CMI) at the University of Namur, Belgium in 1995. He is currently Full Professor of Chemistry, Member of the Royal Academy of Belgium, Fellow of the Royal Society of Chemistry, UK and Life Member of Clare Hall College, University of Cambridge. He is also Changjiang Professor at Wuhan University of Technology and an "Expert of the State" in the frame of "Thousands Talents" program, China. His current research fields include the synthesis, the property study and the molecular engineering of organized, hierarchically porous and bio-inspired materials, living materials and leaf-like materials and the immobilization of bio-organisms for artificial photosynthesis, (photo)Catalysis, Energy Conversion and Storage, Biotechnology, Cell therapy and Biomedical applications. 


\section{Graphical Abstract}

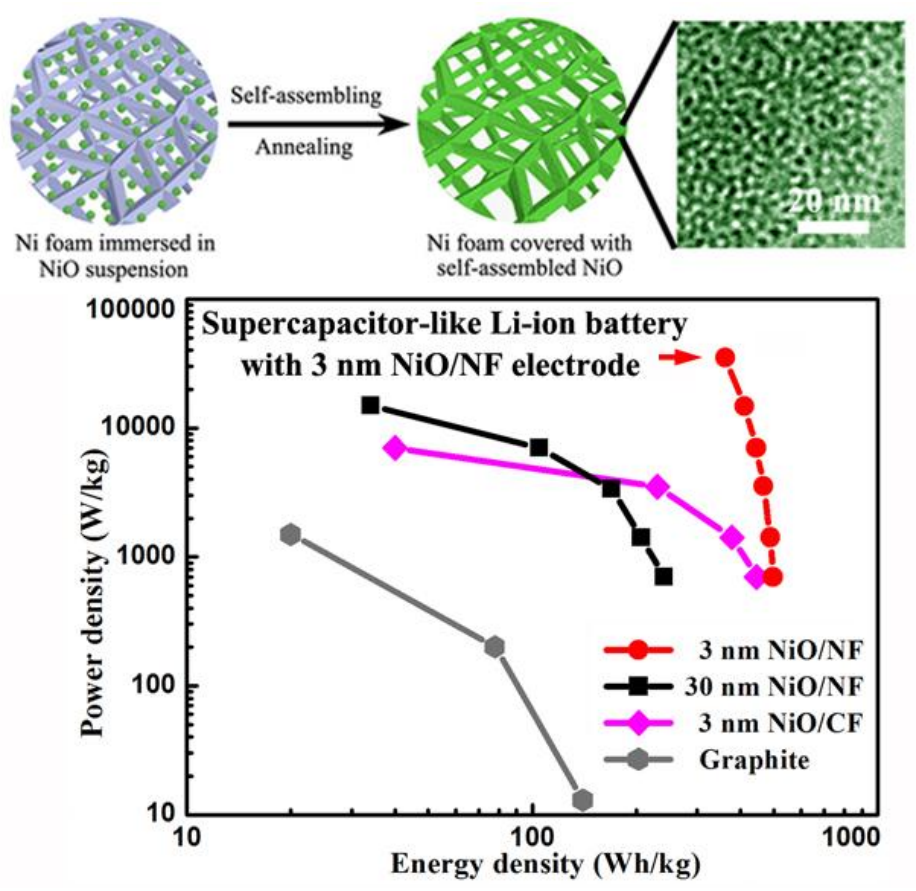

\section{The table of contents}

A binder-free 3D interconnected macro-mesoporous $\mathrm{NiO}$ electrode for rapid ion transfer and ultra-short solid-phase ion diffusion has been developed via self-assembly of $3 \mathrm{~nm} \mathrm{NiO}$ nanodots on macroporous nickel foam. The electrode enables Li-ion storage battery working with supercapacitor rate capability while maintaining high battery capacity. This work described here highlights a new approach to fabricate high-performance electrochemical energy storage devices with both high power as well as energy density. 